\title{
Optical Science and Engineering in Canada
}

\author{
C. P. Grover, FELLOW SPIE \\ National Research Council Canada \\ Ottawa, Ontario K1A 0R6 \\ Canada
}

The recent innovations in the field of lasers, optical fibers, and optical materials and the associated ingenious video microprocessor-based technologies have established optics as a distinct and affluent discipline of science similar to the field of electronics. The evolution of optical science and engineering in Canada, however, has been rather slow. The Canadian scientific community has continued to be closely knit to its southern neighbor, the United States. In addition to many collaborative scientific and technological endeavors, Canadian researchers depend heavily on the American setup when it comes to scientific conferences and publications. The field of optics is no exception. The Canadian optics community is convincingly intertwined with its American counterpart.

Canada is a large country with a small population. A professional society for optics does not exist in Canada, nor is there a journal exclusively devoted to this field. The only option open to optical scientists and engineers who wish to publish locally is the immutable Canadian Journal of Physics. This monthly periodical, published under the auspices of the National Research Council (NRC), the leading R\&D organization in Canada, has a linkage to the Canadian Association of Physicists (CAP). The objectives of CAP include the advancement of the science of physics and the promotion of the use of physical discoveries in the interest of mankind. CAP has 13 divisions including the Optical Physics Division, which is the local professional society for optical scientists and engineers. The present membership of CAP stands at about 1600, with 88 of those members of the Optical Physics Division. ${ }^{1}$ By comparison, the Optical Society of America has 406 Canadian members from nine provinces, and over $82 \%$ of the members live in Ontario and Québec. ${ }^{2}$ SPIE has an enrollment of 292 Canadian members including two fellows of the society. ${ }^{3}$ Canada is a member of the International Commission for Optics (ICO).

Over the years, the NRC, a federal government funded research agency, has been the center of optics research in Canada. The "desirability of an optical laboratory on the lines of those at the Bureau of Standards and the National Physical Laboratory" was the rationale used to establish a photometric laboratory at the NRC in the early 1930 s. ${ }^{4}$ Efforts to expand the optics activities into other fields such as colorimetry, photographic science, interferometry, and instrumental optics continued during the war and in the post-war eras. The modest progress in optics, with activities located in Canadian universities and government laboratories, is crowned by the outstanding achievements in spectroscopy, the field in which Canada is considered a world authority. Gerhard Herzberg's Nobel Prize in 1971 in this field demonstrates this leadership role. In the early 1980s, the NRC was still looking into the possibility of strengthening and expanding research activities in modern optics with an emphasis on electro-optics. It established a task force in 1984, headed by Gunter Wyszecki, to develop a general proposal for the implementation of a national research program in optics. The task force, while recommending the creation of an Institute of Optics within the framework of the NRC, noted in its report:

When the field of optics is taken as a whole with its numerous disciplines (Appendix V) that are not only pursued as scientific endeavours in research laboratories but also as basic technologies in industry, the Canadian effort as it now exists is far from being adequate....

Current Canadian efforts in the field of optics are diffuse and fragmented. Although some areas such as lasers, spectroscopy and fibre-optic communication are vigorously pursued by a number of centres of excellence, the scope and depth of the research activities must be increased significantly in many areas of optics that have a direct bearing on industrial applications. ${ }^{5}$

The Institute of Optics was founded in June 1984 as a new division of the NRC. It was subsequently turned into a notfor-profit corporation called the National Optics Institute (NOI), and it became a component of the subsidiary agreement between the governments of Canada and Québec on scientific and technological development. ${ }^{6}$ The NOI is currently funded jointly by the two governments on the premise that it will eventually become self-financing.

It is with great delight that I present to the readers of Optical Engineering recent Canadian activities in the field of optical science and engineering. Papers were solicited from researchers engaged in R\&D in industry, universities, and government laboratories across Canada, from Victoria, British Columbia, to Saint John's, Newfoundland. However, all papers submitted for publication came from the three most 
populous provinces: Quebec (23 papers), Ontario (16 papers), and British Columbia (1 paper). Out of the forty papers received, thirty-four were accepted for publication in this special issue.

The papers are grouped into the fields of fiber and waveguide lasers, holography, image analysis, machine vision, metrology, optical fiber parameters, optical inspection, optical waveguides, and pattern recognition. Other topics representing the current state of the art of optical science and engineering research in Canada are gradient index optics, local-area networks, mathematical modeling, optical materials, photoacoustic spectroscopy, solid angle functions, solid state lasers, and underwater imaging.

The prominent contributing institutions from the province ofQuébec include: the Canadian Marconi Company, Montréal; Collège Militaire Royal, St. Jean; Defence Research Establishment Valcartier, Québec City; Ecole Polytechnique de Montréal; F.-X. Garneau College, Québec City; NRC's Industrial Materials Institute, Montréal; Laval University, Québec City; Montréal Heart Institute; NOI, Québec City; Stentor Resource Center, Montréal; University of Montréal; and University of Québec at Hull. Papers from the province of Ontario were contributed from organizations such as: A. J. Schindler Communications Inc., Ottawa; Canadian Instrumentation and Research Limited, Burlington; Communications Research Centre, Ottawa; Diffracto Limited, Windsor; Digital Equipment of Canada, Ottawa; Fibernet, Ottawa; NRC's Institute for Information Technology, Ottawa; University of Ottawa; and the University of Toronto. The only contribution coming from western Canada is from the University of Victoria, British Columbia. The majority of the contributing research centers are located within the $1200-\mathrm{km}$ corridor from Windsor, Ontario, to Québec City, Québec.

Editor Brian J. Thompson, in one of his recent editorials, noted that "critical to a first class journal is the paper review process, and specifically the reviews." In the spirit of these sentiments, all the papers went through a rigorous review process involving expert scientists in the field as referees. In this respect, my special thanks go to over 95 referees from 45 research institutions in Canada, the United States, France, and India. I was fascinated by the utmost sense of cooperation and teamwork displayed by all referees. I was rarely disappointed due to the inability of a reviewer to carry out the review. The review process we adopted involved contacting the potential reviewers ahead of time by telephone. If necessary, a paper was assigned to more than two referees from the outset and, in certain cases, up to five referees were approached. In this respect, I thank Bob McKim, Heather Matchett, and Gloria Dumoulin for their diligent handling of the telephone and facsimile correspondence, which was the key element to the timely accomplishment of this project.
Finally, I wish to express my sincere gratitude to all authors for their support and cooperation in the realization of this first feature issue on Optical Science and Engineering in Canada in Optical Engineering. It is my sincere hope that this cooperation will continue in the future and that a Canada issue will become a regular feature in Optical Engineering.

\section{References}

1. Personal Communication, Canadian Association of Physicists, Suite 903, 151 Slater Street, Ottawa, Canada K1P 5H3 (May 1993).

2. 1993-1994 Membership Directory, The Optical Society of America, 2010 Massachusetts Avenue NW, Washington, DC 20036-1023.

3. 1993 SPIE Directory for Members, SPIE-The International Society for Optical Engineering, P.O. Box 10, Bellingham, WA 98227-0010.

4. W.E.K. Middleton, Physics at the National Research Council of Canada, 1929-1952, pp. 37-38, Wilfrid Laurier University Press (1979).

5. "Proposed Institute of Optics," Steering Committee and Task Force Report, pp. 12, 13, 16, National Research Council Canada (May 1984).

6. "Canada-Québec subsidiary agreement on scientific and technological development 1984-1990," Direction générale des publications gouvernmentales du ministère des Communications du Québec (1985).

7. Brian J. Thompson, "Thank you reviewers," Opt. Eng. 31(7), p. 1397 (1992).

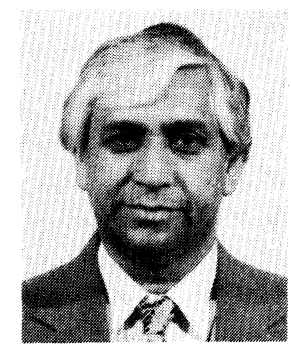

C. P. Grover obtained his BSc Hons. and MSc degrees in physics from the University of Delhi, India; and a PostMSc diploma in applied optics from the Indian Institute of Technology. He received his Docteur d'Etat ès Sciences (DSc) degree from the University of Paris. He worked at the National Physical Laboratory of India from 1966 to 1970 , the Institut d'Optique, Paris, from 1970 to 1973 , the CER-CEM, France, from 1974 to 1975 , and the Indian Space Research Organization from 1975 to 1978 . He immigrated to Canada in 1978 and worked at the University of Toronto and Laval University before joining the National Research Council (NRC) in 1981, where he continues to work as a senior scientist. He was a member of the NRC's task force on optics. He was a leading player in the establishment of the Institute of Optics, where he was its acting director. He was also the founding scientific director of the National Optics Institute. He is a fellow of the Optical Society of America and of SPIE. 